\title{
The incidence, prevalence, and survival rate of thromboangiitis obliterans in Korea: a retrospective population-based study
}

\author{
Bareun Choi ${ }^{1}$, Shin Yi Jang ${ }^{2}$, Seong-Kyong Kim ${ }^{3}$, Nari Kim ${ }^{4}$, Kyeongsug Kim ${ }^{4}$, Dong Kyu Kim ${ }^{5}$ \\ ${ }^{1}$ Department of Physical Medicine and Rehabilitation, Korea University Anam Hospital, 73 Goryeodae-ro Seongbuk-gu, Seoul, Republic of Korea; \\ ${ }^{2}$ Imaging Center, Heart Vascular Stroke Institute, Samsung Medical Center, 81 Irwon-ro, Kangnam-gu, Seoul, Republic of Korea; ${ }^{3}$ Departmentof \\ Orthopedic Surgery, Samsung Medical Center, 81 Irwon-ro, Kangnam-gu, Seoul, Republic of Korea; ${ }^{4}$ Department of Nursing, Samsung Medical \\ Center, 81 Irwon-ro, Kangnam-gu, Seoul, Republic of Korea; ${ }^{5}$ Department of Rehabilitation Medicine, Konkuk University Chungju Hospital, \\ Konkuk University School of Medicine, 82 Gugwon-daero, Chungju, Republic of Korea \\ Contributions: (I) Conception and design: B Choi, SY Jang; (II) Administrative support: K Kim, DK Kim; (III) Provision of study materials or patients: \\ SY Jang, N Kim; (IV) Collection and assembly of data: SY Jang, SK Kim; (V) Data analysis and interpretation: B Choi, SY Jang, SK Kim, N Kim, K \\ Kim, DK Kim; (VI) Manuscript writing: All authors; (VII) Final approval of manuscript: All authors. \\ Correspondence to: Shin Yi Jang, RN, PhD. Imaging Center, Heart Vascular Stroke Institute, Samsung Medical Center, 81 Irwon-ro, Kangnam-gu, Seoul, \\ 06351, Republic of Korea. Email: bautai.jang@samsung.com; Dong Kyu Kim, MD, PhD. Department of Rehabilitation Medicine, Konkuk University \\ Chungju Hospital, Konkuk University School of Medicine, 82 Gugwon-daero, Chungju, 27376, Republic of Korea. Email: peyous@daum.net.
}

Background: Few studies used nationwide data to assess the age-standardized prevalence rate, incidence rate, 10-year survival rate, and death risk of thromboangiitis obliterans (TAO; Buerger's disease).

Methods: Data for 24,392 patients who had newly diagnoses related to TAO (I73.1) from 2006 through 2017 were extracted from the National Health Insurance Service in Korea. The age-standardized prevalence rate, incidence rate, 10-year survival rate, and death risk of TAO were analyzed.

Results: The mean (standard deviation) age of TAO patients overall was 62.0 (15.7) years; 61.3 (15.4) in males and $63.2(16.1)$ in females $(\mathrm{P}<0.001)$. The proportion of patients older than 50 years old was about $80 \%$ overall. The proportion patients who died of TAO was $28.1 \%$. Overall, the age-standardized prevalence rate of TAO decreased from 11.1 persons per 100,000 persons in 2006 to 8.43 persons in 2017, and overall, the incidence rate of TAO decreased from 6.07 persons in 2006 to 3.38 persons in 2017. The age-standardized prevalence rate and incidence rate in males were higher than that in females. The 10-year survival rate of TAO was about $65 \%(60.7 \%$ in males and $72.5 \%$ in females). The adjusted hazard ratio increased significantly with older age, male sex, hypertension, diabetes mellitus, myocardial infarction, heart failure, ischemic stroke, hemorrhagic stroke, chronic kidney disease, and malignant neoplasm.

Conclusions: The 10-year survival rate of TAO was about $65 \%$. Even though the age-standardized prevalence rate and incidence rate of TAO is decreased during the study period, the adjusted hazard ratio showed significantly increases with age and with male sex after adjustment for comorbidities.

Keywords: Prevalence; incidence; survival; death risk; thromboangiitis obliterans (TAO)

Submitted Jun 23, 2020. Accepted for publication Aug 30, 2020.

doi: $10.21037 / \mathrm{cdt}-20-582$

View this article at: http://dx.doi.org/10.21037/cdt-20-582

\section{Introduction}

Thromboangiitis obliterans (TAO; Buerger's disease) is a nonatherosclerotic vascular disease causing recurring, progressive acute and chronic inflammation, and thrombosis in small and medium-sized arteries. TAO showed a distinct clinical trial in a young man with a history of excessive smoking: claudication of the limbs, Raynaud's phenomenon, and migratory superficial vein thrombophlebitis (1). Arterial angiography is helpful for diagnosing of TAO, which is characterized by a smooth and a gradually diminishing segmental lesion of the distal vessel and collateral vessels, 
like a corkscrew. Unlike atherosclerosis of the arteries in the extremities, the proximal large arteries are unaffected, and the internal diameter is smooth (2). The main symptoms of $\mathrm{TAO}$ are pain in the affected areas with claudication, cold sensitivity, absence of peripheral pulse, extremities cyanotic blue or reddish blue color changes in the extremities, and thin or shiny skin. Ulceration and gangrene in the extremities are common complications. TAO leads to vasculitis and ischemic changes in the distal parts of limbs that can eventually leads to amputation of the extremities (3). Few studies have reported the prevalence, incidence, survival, and death risk of TAO in Korea. Therefore, we used Korean National Health Insurance Benefit records between 2006 and 2017 to assess the prevalence, incidence, survival, and death risk for TAO in Korea. We present the following article in accordance with the STROBE reporting checklist (available at http://dx.doi.org/10.21037/cdt-20$582)$.

\section{Methods}

\section{Study population}

Data were collected from the Korean National Health Insurance benefit records from 2006 through 2017 $(n=24,392$; ratio of male to female $=2: 1)$. A main diagnosis was extracted from the records of the Korean National Health Insurance benefit system when the data contained a primary diagnosis based on complaints and symptoms without confirmation during the period of treatment. The data consisted of primary diagnoses related to TAO (I73.1) according to the 10th revision of the International Statistical Classification of Diseases and Related Health Problems (ICD-10), irrespective of Olin's criteria (2). We excluded atherosclerosis (ICD-10: I70). In this study, we also used the death data for Korean people from 2006 through 2018.

\section{Definition of variables}

Age was categorized as 0-9, 10-19, 20-29, 30-39, 40-49, $50-59,60-69,70-79$, and 80 years or older.

\section{Comorbidities}

We defined comorbidities from primary and secondary diagnoses: hypertension (ICD-10: I10, I11, I12, I13, I15); diabetes mellitus (ICD-10: E10, E11 E12, E13, E14); myocardial infarction (ICD-10: I21, I22, I25.2); heart failure (ICD-10: I11.1, I50, I97.1); ischemic stroke (ICD10: I63, I64); hemorrhagic stroke (ICD-10: I60, I61, I62); chronic kidney disease (ICD-10: N18, N19); and malignant neoplasm (ICD-10: C00-C97).

\section{Statistical analysis}

The differences in characteristics were analyzed using the Student's $t$-test for continuous variables and the $\chi^{2}$ test for categorical variables. The age-standardized prevalence and incidence of TAO were calculated with the direct method using the beneficiaries of health insurance from the Korean National Health Insurance Statistical Yearbook from 2006 through 2017 and the estimated Korean population in 2015 as a reference (4). The Kaplan-Meier method was also used with log-rank tests to compare survival among patients with TAO by age group and sex. Simple and multiple Cox proportional hazards analyses were carried out using the variables of age, sex, and comorbidities (hypertension, diabetes mellitus, myocardial infarction, heart failure, ischemic stroke, hemorrhagic stroke, chronic kidney disease, and malignant neoplasm).

The study was conducted in accordance with the Declaration of Helsinki (as revised in 2013). The study was approved by Institutional Review Board (IRB) of Samsung Medical Center (No. 2018-03-023). And informed consent was exempted. Because this study does not exceed the minimum risk for the subject. The exemption of consent does not adversely affect the rights or well-being of the study subject. It is practically impossible to obtain the consent from the subjects during the timeframe of research process. There is no reason to presume the subject's refusal to consent. Even if we do not give consent, the risk level for the subjects is extremely low.

\section{Results}

The mean age (standard deviation) of TAO patients overall was $62.0(15.7)$ years, $61.3(15.4)$ years in males and 63.2 (16.1) years in females $(\mathrm{P}<0.001)$. The proportion of TAO patients overall who were $\geq 50$ years old was about $80 \%$. The proportion of comorbidities with $\mathrm{TAO}$ was $8.87 \%$ with hypertension, $8.20 \%$ with diabetes mellitus, $0.31 \%$ with myocardial infarction, $0.50 \%$ with heart failure, $1.12 \%$ with ischemic stroke, $0.04 \%$ with hemorrhagic stroke, $0.38 \%$ with chronic kidney disease, and $0.27 \%$ with malignant neoplasm. The proportion of patients who died in TAO 
Table 1 Distribution of general characteristics and comorbidities by sex and death risk from thromboangiitis obliterans $($ TAO) $(\mathrm{n}=24,392)$

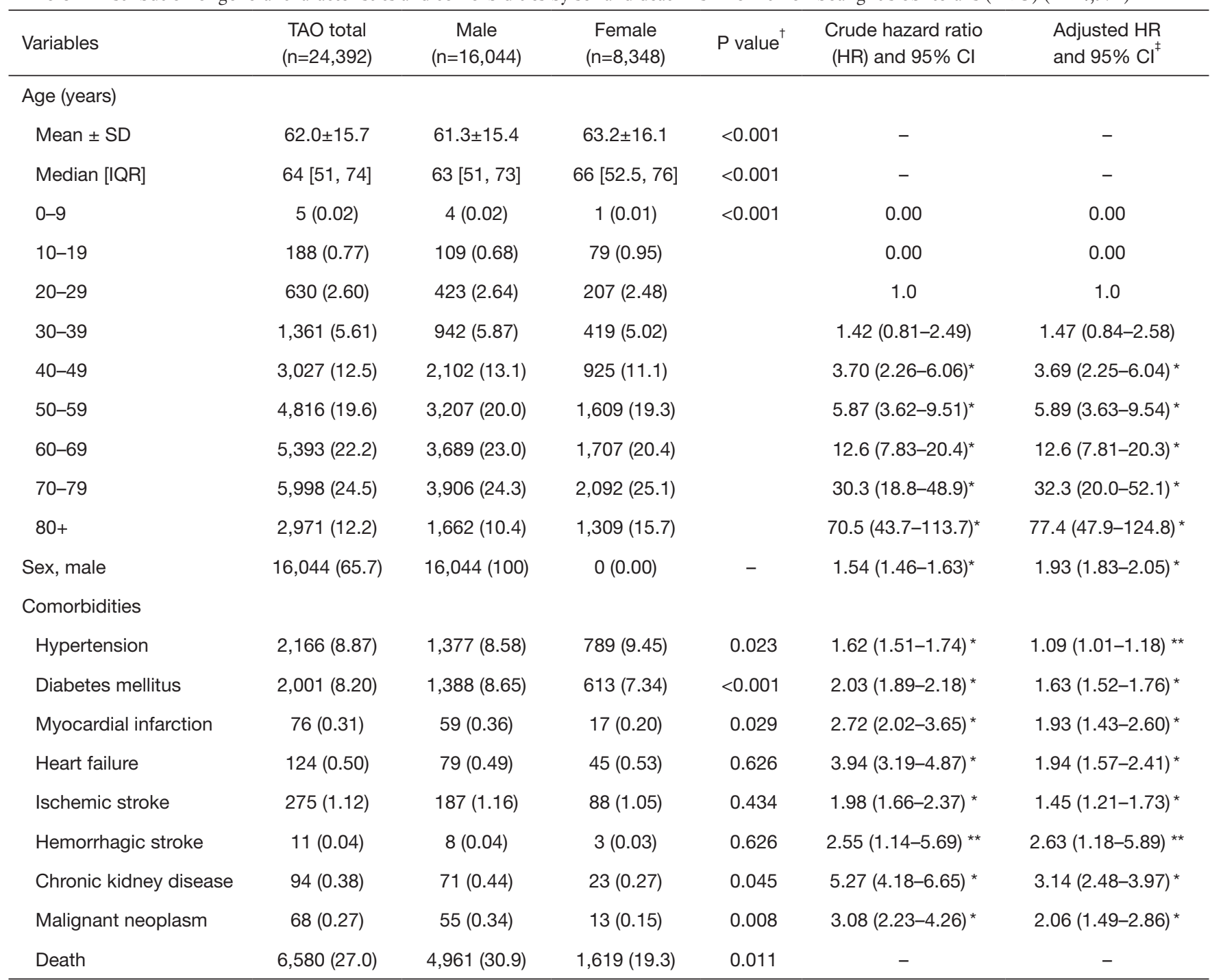

Data are shown as mean $\pm \mathrm{SD}$, median $[\mathrm{IQR}]$, or number (percentage). ${ }^{\dagger}$, Student's $t$-test or $\chi^{2}$ test; ${ }^{\ddagger}$, estimated by Cox proportional Hazard model analysis using the variables indicated in the table; ${ }^{*}, \mathrm{P}<0.001$; ${ }^{\star *}, \mathrm{P}<0.0001$. SD, standard deviation; IQR, interquartile range.

was $27.0 \%$. The adjusted hazard ratio (HR) of death from TAO by age group was 3.69 [95\% confidence interval (CI): 2.25-6.04] among 40-49 years old, 5.89 (95\% CI: 3.63-9.54) among 50-59 years old, 12.6 (95\% CI: 7.81-20.3) among 60-69 years old, 32.3 (95\% CI: 20.0-52.1) among 7079 years old, and 77.4 (95\% CI: 47.9-124.8) among people 80 years or older. The adjusted HR of death from male TAO was 1.93 (95\% CI: 1.83-2.05). The adjusted HR of death from TAO in the presence of underlying diseases was 1.09 (95\% CI: 1.01-1.18) with hypertension, 1.63 (95\% CI: 1.52-1.76) with diabetes mellitus, 1.93 (95\% CI: 1.43-2.60) with myocardial infarction, 1.94 (95\% CI: 1.57-2.41) with heart failure, 1.45 (95\% CI: 1.21-1.73) with ischemic stroke, 2.63 (95\% CI: 1.18-5.89) with hemorrhagic stroke, 3.14 (95\% CI: 2.48-3.97) with chronic kidney disease, and 2.06 (95\% CI: 1.49-2.86) in malignant neoplasm (Table 1).

Overall, the age-standardized prevalence of TAO decreased from 11.1 persons per 100,000 persons in 2006 to 8.43 persons per 100,000 persons in 2017 . The agestandardized prevalence of TAO in males also decreased from 18.1 persons per 100,000 in 2006 to 11.8 persons per 100,000 in 2017. However, the age-standardized prevalence of TAO in females increased from 4.17 persons per 100,000 persons in 2006 to 4.78 persons per 100,000 in 2017 


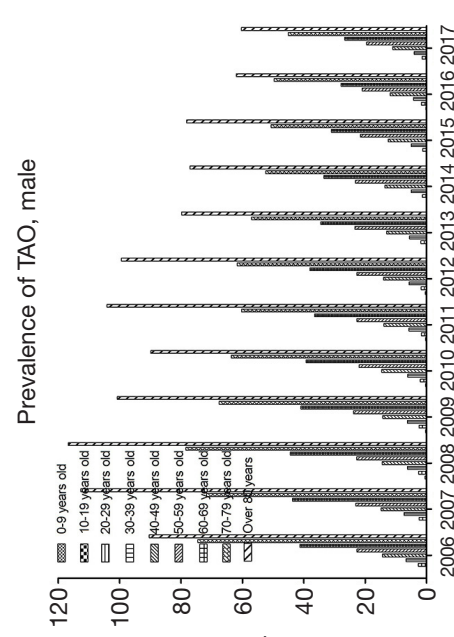

$\cup \quad 000$ '00L/suosiəd 'әэиә|еләлd

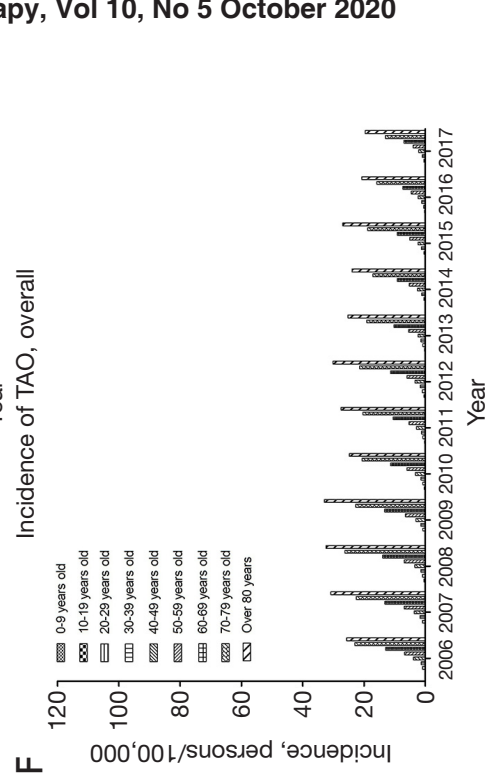

Ш

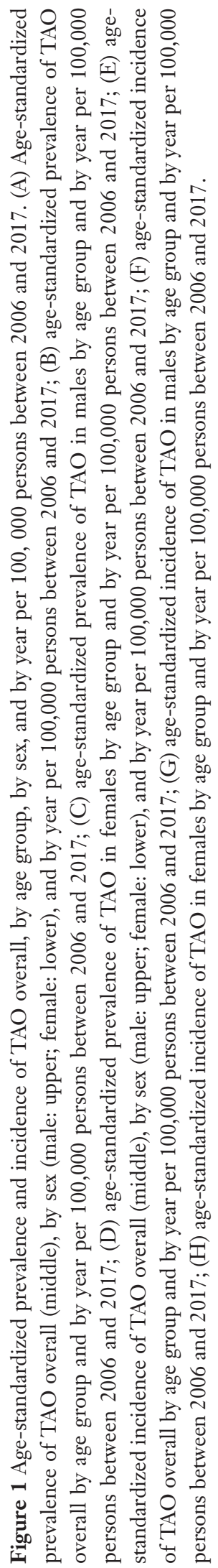

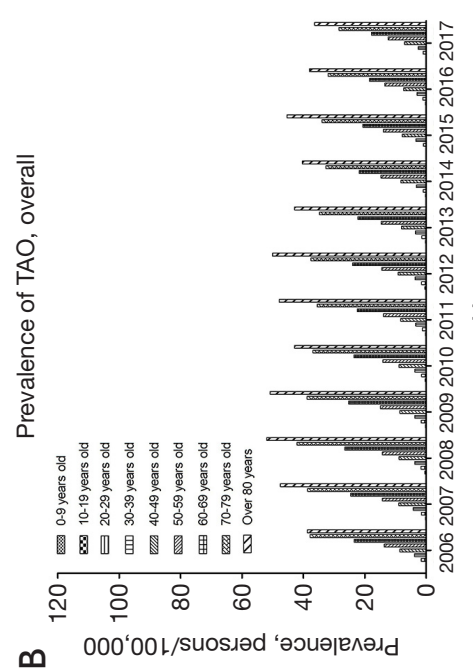

ఐ

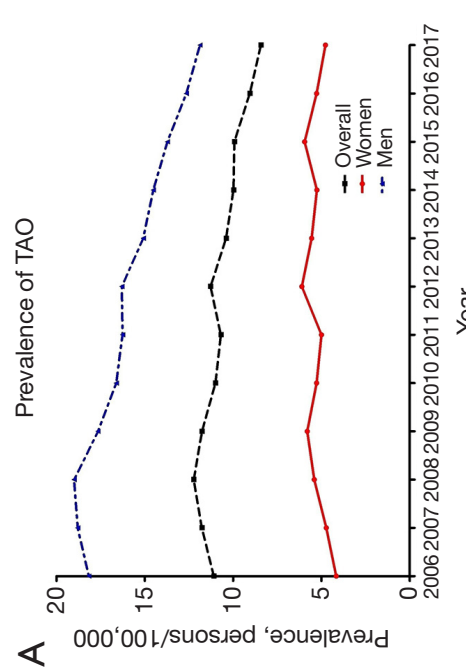

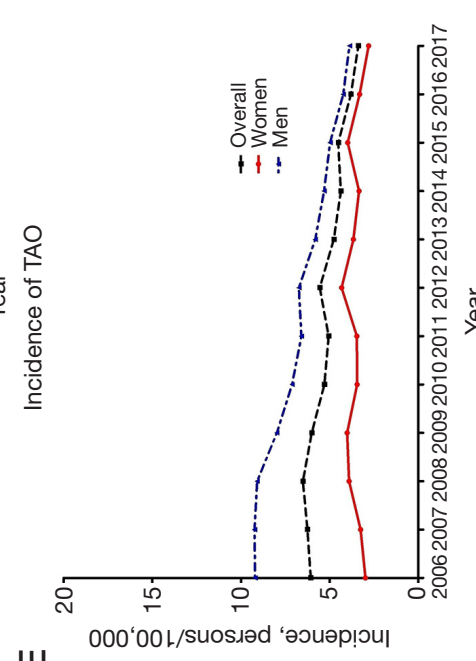

ш

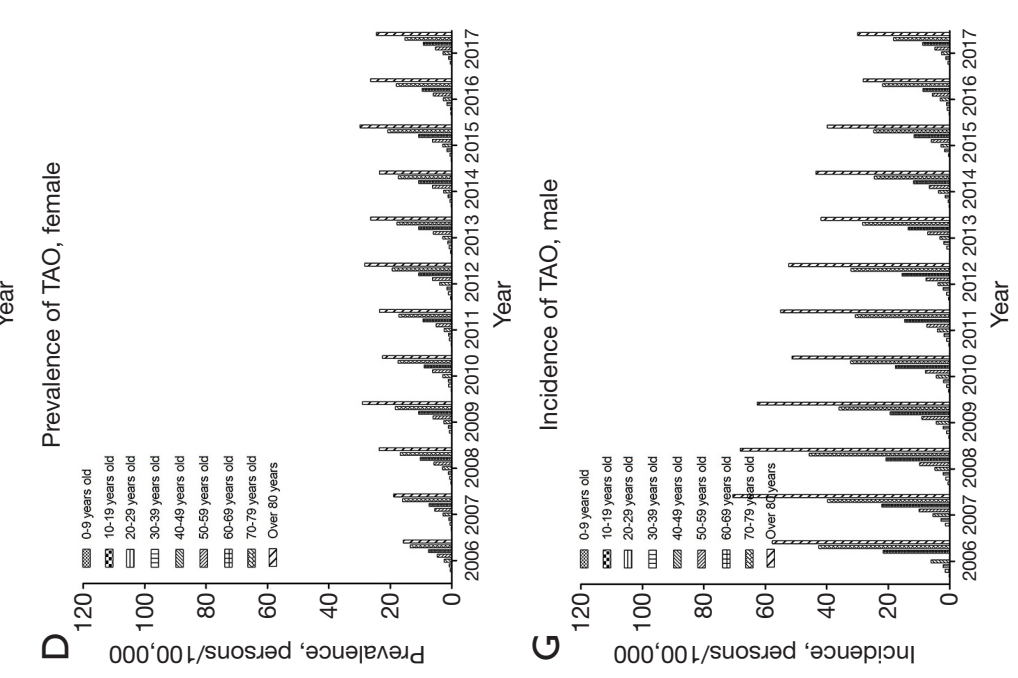

工 000‘00L/suosıəd 'әэuәр!อu|

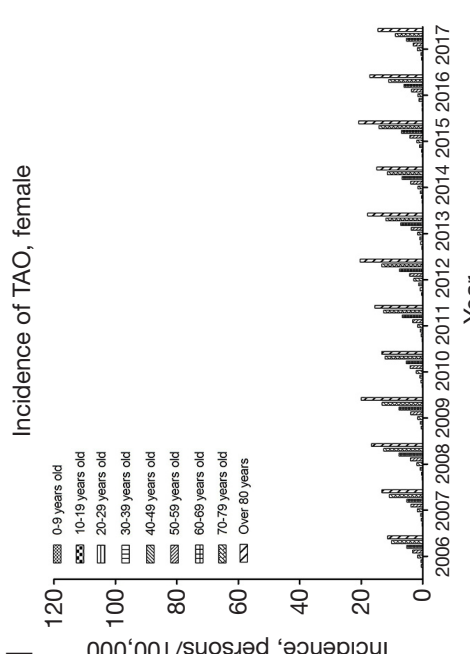



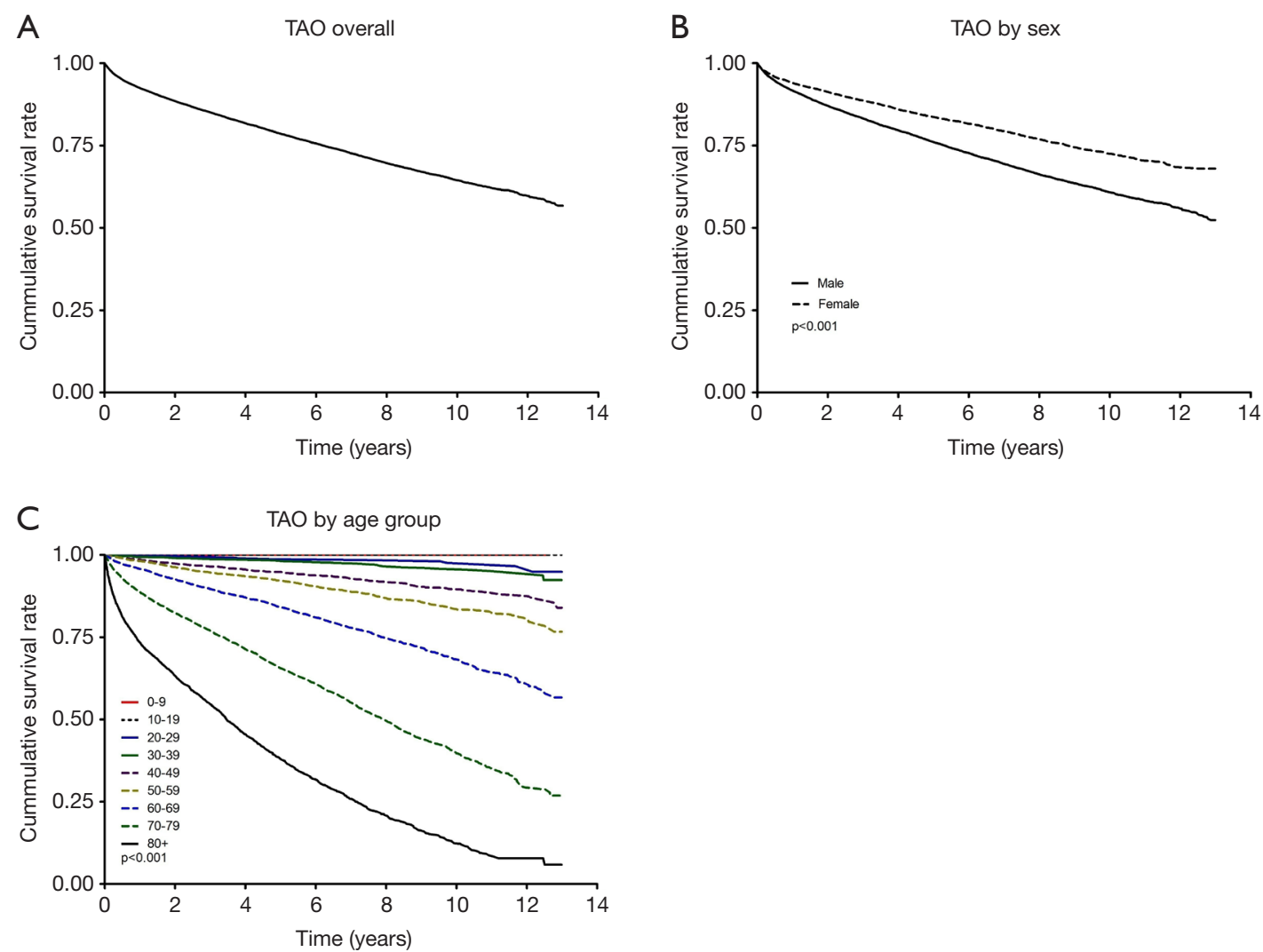

Figure 2 Survival curve of TAO overall (A), by sex (B, P<0.001), and by age group $(\mathrm{C}, \mathrm{P}<0.001)$ from 2006 through 2018.

(Figure $1 A, B, C, D$ and Table $S 1$ ). Overall, the agestandardized incidence of TAO decreased from 6.07 persons per 100,000 in 2006 to 3.38 persons per 100,000 in 2017. The age-standardized incidence of TAO in males decreased from 9.21 persons per 100,000 in 2006 to 3.89 persons per 100,000 in 2017 , and the age-standardized incidence of $\mathrm{TAO}$ in females was 2.98 persons per 100,000 in 2006 and 2.81 persons per 100,000 in 2017 (Figure $1 E, F, G, H$ and Table S2).

Figure $2 A$ shows the survival rates of TAO from 2006 through 2018. The 10-year survival rate with TAO was 64.4\% (95\% CI: 63.6-65.2\%). The 10-year survival rate by sex was $60.7 \%$ (95\% CI: 59.8-61.7) in males and $72.5 \%$ (95\% CI: $71.2-73.9 \%$ ) in females (Figure 2B). The 10-year survival rate for the $0-9,10-19,20-29,30-39,40-49,50-59,60-69$, $70-79$, and 80 years or older groups was $100 \%, 100 \%, 97.6 \%$ (95\% CI: 95.3-98.7\%), 95.8\% (95\% CI: 94.1-96.9\%), 89.6\% (95\% CI: 88.1-90.8\%), 83.5\% (95\% CI: 82.1-85.0\%), 68.2\% (95\% CI: $66.5-69.9 \%), 39.7 \%$ (95\% CI: $37.8-41.6 \%$ ), and 12.4\% (95\% CI: 10.4-14.6\%), respectively (Figure 2C).

\section{Discussion}

The adjusted HR for TAO increased with older age, male sex, and comorbidities (hypertension, diabetes mellitus, myocardial infarction, heart failure, ischemic stroke, hemorrhagic stroke, chronic kidney disease, and malignant neoplasm). Few studies have found HRs for TAO. However, a study by Le Joncour et al. of 224 patients in a French TAO network from 1970 to 2016 demonstrated a different HR results from ours: a non-significantly lower HR with male sex, hypertension, and dyslipidemia (5). This difference could be due to ethnic differences or their study design, which used Papa's criteria (6). Our study includes only Asian patients and a diagnosis of I73.1 in ICD-10 in a national collection of big data, irrespective of Buerger's disease diagnosis criteria, whereas the Le Joncour et al. study population contained mostly white patients with TAO diagnosed by the Papa's criteria than non-white.

Our results demonstrate that the male age-standardized prevalence and incidence of TAO decreased from 2006 through 2017. Although research into the prevalence and 
incidence of TAO research using a national collection of big data is extremely rare, the results from $78 \mathrm{TAO}$ patients in northern Thailand from 1988 to 2002 (7) and 158 patients in Taiwan from 2002 to 2011 (8) correspond well with our results; the prevalence and incidence of TAO also decreased over time in those studies. Few studies have reported the age-standardized prevalence and incidence of TAO by sex. Therefore, the results in this study cannot be compared with those from other geographic or ethnic groups. Considering that the incidence of TAO could be correlated with smoking (9-11), it is relevant that the daily smoking rate in Korean decreased from about 23\% in 2007 to about $17 \%$ in 2017 , according to Organization for Economic Cooperation and Development indicators (12). In the same period, the smoking rate in males decreased from $25.3 \%$ to $22.3 \%$, and the smoking rate in females increased from $5.3 \%$ to $6.0 \%$, according to the 2017 Korea National Health and Nutrition Examination Survey (13).

TAO was diagnosed more commonly in males than females. In our results, males had about a two times higher incidence of TAO than females, which is consistent with the higher male distribution of TAO found in Taiwan (80.5\%) (8).

In this study, the 10-year survival rate of TAO was about $65 \%$. This is similar to the amputation-free 10 -year survival rate in a French nationwide study, which was around $70 \%$ (5). We cannot directly compare our 10-year survival rate because no other studies have reported the 10-year survival rate by sex and age group using a nationwide collected of big data. In this study, the 10-year survival rate was lower in older age groups, but this result was similar to the overall death rate pattern in Korea found in Statistics Korea data from 2014 (14). The 10-year survival rate with TAO was lower in males than in females because Korean males overall have a higher 10 -year mortality rate and lower life expectancy than Korean females $(14,15)$. For males, the HR for TAO was also significantly higher than for females.

Our study has several limitations. First, the National Health Insurance benefit records might have missed TAO patients who did not use medical services or paid for their own medical expenses. For this reason, the prevalence or incidence of TAO in this study might be under- or overestimated. Second, we could not evaluate the severity of TAO, the risk factors such as smoking habits $(16,17)$ or clinical data such as laboratory findings from blood tests, the Allen's test, angiograms, medical/surgical treatments, medical history taking (5), or amputation information (1) because of data limitations.

\section{Conclusions}

Overall, the age-standardized prevalence and incidence of TAO in 2017 were about 9 and about 4 persons per 100,000 persons, respectively. Although the male age-standardized prevalence and incidence decreased during the study period, they were still higher proportion in males than in females. The 10 -year survival rate with TAO was about $65 \%$. Adjusted HRs increased significantly with age, male sex, and comorbidities.

\section{Acknowledgments}

This study used data from the National Health Insurance Service (research management number NHIS-2019-1-147), but the study results are not related to the National Health Insurance Service.

Funding: None.

\section{Footnote}

Reporting Checklist: The authors present the study in accordance with the STROBE reporting checklist. Available at http://dx.doi.org/10.21037/cdt-20-582

Data Sharing Statement: Available at http://dx.doi. org/10.21037/cdt-20-582

Conflicts of Interest: All authors have completed the ICMJE uniform disclosure form (available at http://dx.doi. org/10.21037/cdt-20-582). The authors have no conflicts of interest to declare.

Ethical Statement: The authors are accountable for all aspects of the work in ensuring that questions related to the accuracy or integrity of any part of the work are appropriately investigated and resolved. The study was conducted in accordance with the Declaration of Helsinki (as revised in 2013). The study was approved by Institutional Review Board (IRB) of Samsung Medical Center (No. 2018-03-023). And informed consent was exempted. Because this study does not exceed the minimum risk for the subject. The exemption of consent does not adversely affect the rights or well-being of the study subject. It is practically impossible to obtain the consent from the subjects during the timeframe of research process. There is no reason to presume the subject's refusal to consent. Even if we do not give consent, the risk level for 
the subjects is extremely low.

Open Access Statement: This is an Open Access article distributed in accordance with the Creative Commons Attribution-NonCommercial-NoDerivs 4.0 International License (CC BY-NC-ND 4.0), which permits the noncommercial replication and distribution of the article with the strict proviso that no changes or edits are made and the original work is properly cited (including links to both the formal publication through the relevant DOI and the license). See: https://creativecommons.org/licenses/by-nc-nd/4.0/.

\section{References}

1. Puéchal X, Fiessinger JN. Thromboangiitis obliterans or Buerger's disease: challenges for the rheumatologist. Rheumatology (Oxford) 2007;46:192-9.

2. Olin JW. Thromboangiitis obliterans (Buerger's disease). N Engl J Med 2000;343:864-69.

3. Tanaka K. Pathology and pathogenesis of Buerger's disease. Int J Cardiol 1998;66 Suppl 1:S237-242.

4. Jang SY, Seo SR, Park SW, et al. The Prevalence of Marfan Syndrome in Korea. J Korean Med Sci 2017;32:576-80.

5. Le Joncour A, Soudet S, Dupont A, et al. Long-Term Outcome and Prognostic Factors of Complications in Thromboangiitis Obliterans (Buerger's Disease): A Multicenter Study of 224 Patients. J Am Heart Assoc 2018;7:e010677.

6. Papa MZ, Rabi I, Adar R. A point scoring system for the clinical diagnosis of Buerger's disease. Eur J Vasc Endovasc Surg 1996;11:335-9.

7. Laohapensang K, Rerkasem K, Kattipattanapong V. Decrease in the incidence of Buerger's disease recurrence in northern Thailand. Surg Today 2005;35:1060-5.

Cite this article as: Choi B, Jang SY, Kim SK, Kim N, Kim $\mathrm{K}$, Kim DK. The incidence, prevalence, and survival rate of thromboangiitis obliterans in Korea: a retrospective populationbased study. Cardiovasc Diagn Ther 2020;10(5):1238-1244. doi: $10.21037 / \mathrm{cdt}-20-582$
8. Zheng JF, Chen YM, Chen DY, et al. The Incidence and Prevalence of Thromboangiitis Obliterans in Taiwan: A Nationwide, Population-based Analysis of Data Collected from 2002 to 2011. Clinics (Sao Paulo) 2016;71:399-403.

9. Shima N, Akiyama Y, Yamamoto S, et al. A Nonsmoking Woman with Anti-phospholipid Antibodies Proved to Have Thromboangiitis Obliterans. Intern Med 2020;59:439-43.

10. Jiménez-Ruiz CA, Dale LC, Astray Mochales J, et al. Smoking characteristics and cessation in patients with thromboangiitis obliterans. Monaldi Arch Chest Dis 2006;65:217-21.

11. Rahman M, Chowdhury AS, Fukui T, et al. Association of thromboangiitis obliterans with cigarette and bidi smoking in Bangladesh: a case-control study. Int J Epidemiol 2000;29:266-70.

12. OECD (2019), Health at a Glance 2019: OECD Indicators, OECD Publishing, Paris. Available online: https://doi.org/10.1787/4dd50c09-en

13. Korea Health Statistics 2017: Korea National Health and Nutrition Examination Survey (KNHANES VII-2).

14. Shin HY, Lee JY, Song JH, et al. Cause-of-death statistics in the Republic of Korea, 2014. J Korean Med Assoc 2016;59:221.

15. Jo MW, Seo W, Lim SY, et al. The Trends in Health Life Expectancy in Korea according to Age, Gender, Education Level, and Subregion: Using Quality-Adjusted Life Expectancy Method. J Korean Med Sci 2019;34:e88.

16. Igari $\mathrm{K}$, Inoue $\mathrm{Y}$, Iwai $\mathrm{T}$. The Epidemiologic and Clinical Findings of Patients with Buerger Disease. Ann Vasc Surg 2016;30:263-9.

17. Malecki R, Zdrojowy K, Adamiec R. Thromboangiitis obliterans in the 21st century--a new face of disease. Atherosclerosis 2009;206:328-34. 


\section{Supplementary}

Table S1 Age-standardized prevalence and 95\% confidence interval (CI) of thromboangititis obliterans (TAO) overall and by eev (per 100,000)

\begin{tabular}{|c|c|c|c|c|c|c|c|c|c|c|c|c|c|c|c|c|c|c|c|c|c|c|c|c|}
\hline \multirow[b]{2}{*}{ Variables } & \multicolumn{2}{|r|}{2006} & \multicolumn{2}{|r|}{2007} & \multicolumn{2}{|r|}{2008} & \multicolumn{2}{|r|}{2009} & \multicolumn{2}{|r|}{2010} & \multicolumn{2}{|r|}{2011} & \multicolumn{2}{|r|}{2012} & \multicolumn{2}{|r|}{13} & \multicolumn{2}{|r|}{2014} & \multicolumn{2}{|r|}{2015} & \multicolumn{2}{|r|}{2016} & \multicolumn{2}{|r|}{2017} \\
\hline & $\mathrm{n}$ & $\begin{array}{l}\text { Prevalence } \\
(95 \% \mathrm{Cl}) \\
\end{array}$ & $n$ & $\begin{array}{l}\text { Prevalence } \\
(95 \% \mathrm{Cl})\end{array}$ & $n$ & $\begin{array}{l}\text { Prevalence } \\
(95 \% \mathrm{Cl}) \\
\end{array}$ & $n$ & $\begin{array}{l}\text { Prevalence } \\
(995 \% \mathrm{CI})\end{array}$ & $n$ & $\begin{array}{l}\text { Prevalence } \\
(95 \% \mathrm{Cl})\end{array}$ & $n$ & $\begin{array}{l}\text { Prevalence } \\
(95 \% \mathrm{Cl}) \\
\end{array}$ & $\mathrm{n}$ & $\begin{array}{c}\text { Prevalence } \\
(95 \% \mathrm{CI})\end{array}$ & $\mathrm{n}$ & $\begin{array}{c}\text { Prevalence } \\
(95 \% \mathrm{Cl})\end{array}$ & $\mathrm{n}$ & $\begin{array}{l}\text { Prevalence } \\
(95 \% \mathrm{Cl})\end{array}$ & $n$ & $\begin{array}{c}\text { Prevalence } \\
(95 \% \mathrm{Cl})\end{array}$ & $r$ & $\begin{array}{l}\text { Prevalence } \\
(95 \% \mathrm{CI})\end{array}$ & & $\begin{array}{l}\text { Prevalence } \\
(95 \% \mathrm{Cl})\end{array}$ \\
\hline AlI & 3,671 & $11.1(10.7-11.5)$ & 4,031 & $11.7(11.3-12.1)$ & 4,332 & $12.2(11.8-12.6)$ & 4,385 & $11.7(11.3-12.1)$ & 4,325 & $10.9(10.6-11.3)$ & 4,343 & $10.6(10.3-11.0)$ & 4,807 & $11.2(10.9-911.6)$ & 4,633 & $10.3(10.0-10.7)$ & 4,630 & $9.98(9.69-10.2)$ & 4,714 & $9.93(9.64-10.2)$ & 4,498 & $9.05(8.79-9.32)$ & 4,309 & $8.43(8.17-8.68$ \\
\hline $0-9$ years old & 1 & $0.00(0.00-0.04)$ & 1 & $0.00(0.00-0.03)$ & 0 & $0.00(0.00-0.00)$ & 1 & $0.00(0.00-0.04)$ & & $0.00(0.00-0.00)$ & 0 & $0.00(0.00-0.00)$ & & $0.00(0.00-0.00)$ & 0 & $0.00(0.00-0.00)$ & & $0.00(0.00--.00)$ & 1 & $0.00(0.00-0.04)$ & 0 & $0.00(0.00-0.00)$ & 1 & $0.02(0.00-0.06)$ \\
\hline 10-19 years old & 12 & $0.18(0.07-0.29)$ & 15 & $0.23(0.11-0.35)$ & 32 & $0.48(0.31-0.65)$ & 19 & $8(0.15-0.41)$ & 21 & $0.32(0.18-0.46)$ & $2 c$ & $0.30(0.16-0.44)$ & 26 & $0.41(0.24-0.57)$ & 19 & $0.30(0.16-0.44)$ & 15 & $0.25(0.11-0.38)$ & 11 & $0.19(0.07-0.31)$ & 16 & $0.28(0.14-0.42)$ & 9 & $0.16(0.04-0.27)$ \\
\hline $20-29$ years old & 125 & $5(1.36-1.94)$ & 115 & $(1.27-1.84)$ & 124 & $9(1.39-1.99)$ & 118 & $5(1.35-1.95)$ & 107 & $54(1.24-1.83)$ & 87 & $27(1.00-1.54)$ & 101 & $1.49(1.20-1.79)$ & 95 & $41(1.13-1.70)$ & 67 & $0.98(0.74-1.22)$ & 65 & $0.95(0.71-1$. & 75 & $1.09(0.84-1.33)$ & 70 & $1.01(0.77-1$ \\
\hline 30-39 years old & 335 & 3.84(3.43-4.25) & 368 & $4.23(3.79-4.66)$ & 317 & 3.73(3.32-4.414) & 315 & $3.73(3.31-4.14)$ & 312 & 3.73 (3.34-4-.14 & 286 & $3.44(3.04-3.84$ & 30 & $3.66(3.24-4.07)$ & 284 & $3.51(3.10-3.92)$ & 251 & $3.16(2.77-3.55)$ & 262 & $3.35(2.94-3.76)$ & 228 & $2.96(2.57-3.34)$ & 197 & $2.61(2.24-2.97)$ \\
\hline $40-49$ years old & 706 & 7(7.94-9.920) & 747 & (8.31-9.60) & 751 & $5(8.21-9.48)$ & 734 & 7(7.94-9.919) & 762 & $90(8.26-9.53)$ & 720 & (5).7.14-8.96) & 789 & $9.12(8.48-9.76)$ & 706 & $8.06(7.46-8.65)$ & 722 & $8.20(7.60-8.80)$ & 684 & $7.82(7.24-8.441)$ & 640 & $7.35(6.78-7.92)$ & 608 & $7.03(6.47-7.59)$ \\
\hline 50-59 уе: & 739 & $(12.7-14.7)$ & 817 & (13.3- & 855 & $(13.3-15.2)$ & 954 & 9 & 96 & $4.1(13.2-15.0)$ & 101 & $9(13.0-14.7)$ & 1,099 & 14.5 (13.6-615.3 & 1,149 & $14.7(13.8-15.5)$ & 1,184 & $14.7(13.9-15.5)$ & 1,136 & $13.9(13.1-144.7)$ & 1,11 & $13.5(6.78-7.92)$ & 1,036 & $12.4(11.6-13.1)$ \\
\hline $60-69$ years old & 827 & $23.5(21.9-925.1)$ & 901 & $6.6(23.0-26.2)$ & 1004 & 5 (24.9-28.1) & 982 & $2.233 .7-26.8)$ & 938 & $23.5(22.0-25.0)$ & 903 & $22.4(21.0-23.9)$ & 993 & $23.9(22.4-25.4)$ & 956 & $22.2(20.8-23.6)$ & 990 & 21.8 (20.4-23.1) & 1,010 & $20.6(19.4-21.9)$ & 961 & $18.5(17.3-19.6)$ & 975 & $17.8(16.7-18.9)$ \\
\hline $70-79 \mathrm{y}$ & 69 & & 759 & & 882 & & 875 & $6.2-2-2>$ & & $(34.4,>>$ & 89 & & 1,0 & (35. & 98 & $.7(32.5 .5)$ & 950 & $32.6(30.5-3$ & 9 & 33.9 (31. & 958 & 31.9 (29.9- & 893 & $28.4(2$ \\
\hline 80 years or older & 233 & $38.7(33.7-743.6)$ & 308 & $47.5(42.2-252.8)$ & 363 & $52.0(46.6-57.3)$ & 387 & $50.8(45.7-55.9)$ & 349 & 42.9 (38.4-477.4) & 418 & $47.9(43.3-52.5)$ & 473 & $50.0(45.5-54.5)$ & 439 & $42.9(38.8-46.9)$ & 451 & $40.3(36.5-44.0)$ & 552 & $45.3(41.5-49.1)$ & 503 & $38.0(34.6-41.3)$ & 520 & $36.3(33.2-39.4)$ \\
\hline Females & 641 & (3.83-4.52) & 759 & & 899 & & 993 & & 973 & & 949 & & 1,234 & 46) & 1,162 & $5.56(5.23-5.89)$ & 1,153 & $5.26(4.95-5.57)$ & 1,332 & $5.95(5.63-6.28)$ & 1236 & $5.27(4.98-5.57)$ & 1158 & $4.78(4.50-5.06)$ \\
\hline $0-9$ years old & 0 & $0.00(0.00-0.00)$ & 0 & $\begin{array}{l}0.00(0.00-0.00) \\
0\end{array}$ & 0 & $0.00(0.00-0.00)$ & 1 & $0.00(0.00-0.08)$ & 0 & $0.00(0.00-0.00)$ & 0 & $0.00(0.00-0.00)$ & 0 & $0.00(0.00-0.00)$ & 0 & $0.00(0.00-0.00)$ & 0 & $0.00(0.00--.00)$ & 0 & $0.00(0.00-0.00)$ & 0 & $0.00(0.00-0.00)$ & 0 & $0.00(0.00-0.00)$ \\
\hline $10-19$ years old & 4 & $0.11(0.00-0.24)$ & 9 & $0.26(0.06-0.45)$ & 11 & $33(0.12-0.55)$ & 5 & o.14(0.01-0.29) & 7 & $0.22(0.05-0.39)$ & 7 & $0.22(0.05-0.39)$ & 12 & $0.37(0.14-0.60)$ & 13 & $0.44(0.20-0.69)$ & 8 & $0.26(0.06-0.44)$ & 7 & $0.26(0.066-0.45)$ & 8 & $0.29(0.08-0.51)$ & 3 & $0.11(0.00-0.25)$ \\
\hline $20-29$ years & 18 & & 23 & 0 & 24 & 38- & 28 & .48-1.09) & 34 & $20.67-7)$ & 25 & .45-1.06) & 36 & $1.12(0.75-1.4$ & 29 & $89(0.55-1.22)$ & 18 & $0.56(0.30-0.82)$ & 19 & & 13 & $0.39(0.17-0.61)$ & 16 & $0.46(0.22-0.70)$ \\
\hline $30-39$ years old & 37 & $0.85(0.57-1.13)$ & 40 & $0.94(0.64-1.23)$ & 44 & $1.05(0.73-1.36)$ & 44 & $1.05(0.73-1.37)$ & 46 & $1.10(0.77-1.43)$ & 41 & $0.99(0.68-1.30)$ & 62 & $1.55(1.16-1.93)$ & 51 & $1.27(0.91-1.62)$ & 46 & $1.19(0.84-1.53)$ & 60 & $1.57(1.17-1.98)$ & 59 & $1.57(1.17-1.98)$ & 38 & $1.02(0.69-1.35)$ \\
\hline 40-49 уед & 100 & 2 & 115 & & 123 & 2 & 10 & 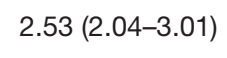 & 120 & & 14 & & 16 & 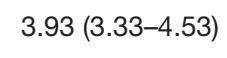 & 124 & ) & 1713 & $2.00(2.11-3.080)$ & 12 & & 1716 & $2.69(2.20-3.19)$ & 120 & $2.81(2.30-30-3.32)$ \\
\hline $50-59$ years old & 127 & $4.70(3.88-5.52)$ & 158 & $5.56(4.69-6.42)$ & 173 & $5.78(4.92-6.64)$ & 193 & $6.06(5.20-6.91)$ & 212 & $6.21(5.37-7.05)$ & 184 & $5.03(4.30-5.76)$ & 238 & $6.28(5.48-7.08)$ & 232 & $5.93(5.17-6.70)$ & 250 & $6.23(5.46-7.01)$ & 256 & $6.28(5.51-7.06)$ & 245 & $5.96(5.21-6.70)$ & 220 & $5.28(4.58-5.98)$ \\
\hline 60-69 years olc & 140 & & 141 & & 202 & 1 & 210 & 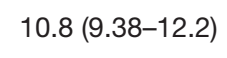 & 18 & $1.05-10.4$ & 19 & 作 & 23 & 10.79 .35 & 23 & To. $1(9.37-12.1)$ & 250 & 10.1(9.441-12:0) & $2 \pi 6^{2}$ & . & 204 & $9.62(8.44-10.8)$ & 261 & $9.27(8.14-10.4)$ \\
\hline 70-79 years & 149 & $(1.12-15.6)$ & 188 & (13.7-18.3) & 207 & & 242 & 6.0-20.6) & 240 & & $25 c$ & 15.0-19.2) & 302 & 17.1-121.5) & $28 \varepsilon$ & $7.8(15.7-19.9)$ & 287 & $17.3(15.3-19.4)$ & 344 & $20.8(18.6-23.0)$ & 302 & $18.0(15.9-20.0)$ & 265 & $15.1(13.3-17.0)$ \\
\hline 80 years or olc & 66 & & 8. & & 115 & & 15 & & 128 & (10.0-20.47) & 14 & 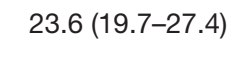 & 187 & & 18 & & 181 & (-27.0) & 248 & & 230 & $26.4(23.0-29.7)$ & 235 & $24.5(21.3-27.6)$ \\
\hline Males & 3,030 & & 3,272 & & 3,433 & & 3,392 & & 3,352 & & 3,394 & & 3,57 & & 3,471 & & 3,477 & & 3,3 & & 3,262 & & 3,151 & \\
\hline $0-9$ years & 1 & $(0.00-0.07)$ & 1 & $0.00(0.00-0.07)$ & 0 & (0.00-0.00) & 0 & (0.0.00-0.00) & & o & 0 & (0.00-00-0.00) & & $10(0.00-0.00)$ & & 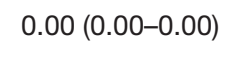 & & $0.00(0.00-0.00)$ & & $0.00(0.00-0.08)$ & 0 & $0.00(0.00-0.00)$ & 1 & $.04(0.00-0.13)$ \\
\hline 10. & 8 & & 6 & & 2 & & 1 & & 1 & & 1 & & & & & & & & & & & & 6 & \\
\hline & 107 & 1-3.2.26) & 92 & .92-2.911) & 100 & $2.13-$ & 90 & (1.94-2.95) & $7:$ & (1.56- & 62 & $.30-2.17$ & 65 & $(1.37-2.28$ & 6 & $(1.40-2.31)$ & 4 & 35 (0.97-1.74) & 46 & 1.63 & 62 & $.68(1.25-2.10)$ & 54 & $.47(1.08-1.86)$ \\
\hline 30-39 years old & 298 & & 328 & & 273 & & 27 & & 26 & & 2. & & 2: & & 2 & & 205 & & 20: & & 169 & 4.25(3.61-4.90) & 159 & $4.07(3.43-4.70)$ \\
\hline & 606 & & 632 & & 62. & & 62 & & 6. & & 6 & & & & & & 6 & & 5 & & 524 & & 488 & \\
\hline & 612 & $22.7(20.9-924.5)$ & 659 & B.1 (21.3-24.8) & 686 & $8(21.1-24.5)$ & 76 & $23.8(22.1-25.5)$ & 749 & $22.0(20.4-23.5)$ & 82 & $22.7(21.2-24.3)$ & 86 & $22.7(21.2-24.2)$ & 91 & 3.4(211.9-24.9) & 934 & $23.2(21.7-24.7)$ & 88 & $21.5(20.1-23.0)$ & 872 & $21.0(19.6-22.4)$ & 816 & $9.5(18.2-20.8)$ \\
\hline & 687 & & 760 & & 802 & & 76 & & 75 & & 76 & & 76 & & 71 & & 72 & & 73 & & 704 & & 714 & \\
\hline & 544 & $74.5(68.2-80.8)$ & 571 & $(65.8-77.5)$ & 675 & 78.4(772.4-84.3) & 633 & 2.3.-72.8. & 635 & $88.6-68.5)$ & 647 & $60.2(55.6-6-64.9)$ & 723 & & 697 & 2.7-61.2) & 663 & 48.4-56.4) & 64 & & 656 & 3-53.4) & 628 & \\
\hline & or & & 223 & & 48 & & 233 & & 27 & & 274 & & 280 & & 252 & & $2 \pi 0$ & & 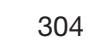 & & 201 & . & 885 & \\
\hline
\end{tabular}

", age-standardized prevalence rates of TAO were calculated according to the direct method using the estimated Korean population in 2015 as a reference. 


\begin{tabular}{|c|c|c|c|c|c|c|c|c|c|c|c|c|c|c|c|c|c|c|c|c|c|c|c|c|}
\hline \multirow{2}{*}{ Varables } & \multicolumn{2}{|r|}{2006} & \multicolumn{2}{|r|}{2007} & \multicolumn{2}{|r|}{2008} & \multicolumn{2}{|r|}{2009} & \multicolumn{2}{|r|}{2010} & \multicolumn{2}{|r|}{2011} & \multicolumn{2}{|r|}{2012} & \multicolumn{2}{|r|}{2013} & \multicolumn{2}{|r|}{2014} & \multicolumn{2}{|r|}{2015} & \multicolumn{2}{|r|}{2016} & \multicolumn{2}{|r|}{2017} \\
\hline & $n$ & Incidence $(95 \% \mathrm{Cl})$ & $n$ & Incidence $(95 \% \mathrm{Cl})$ & $n$ & Incidence $(95 \% \mathrm{Cl})$ & n & Incidence $(95 \% \mathrm{Cl})$ & n & Incidence $(95 \% \mathrm{Cl})$ & $n$ & Incidence $(95 \% \mathrm{Cl})$ & $n$ & Incidence $(95 \% \mathrm{Cl})$ & $n$ & Incidence $(95 \% \mathrm{Cl})$ & $n$ & Incidence $(95 \% \mathrm{Cl})$ & $n$ & Incidence $(95 \% \mathrm{Cl})$ & n & Incidence $(95 \% \mathrm{Cl})$ & $n$ & Incidence $(95 \% \mathrm{Cl})$ \\
\hline All & 3,151 & $6.07(5.78-6.35)$ & 2,062 & $6.25(5.96-6.53)$ & 2,224 & $32.4(28.1-36.6)$ & 2,151 & $6.01(5.74-6.28)$ & 2,030 & $5.30(5.06-5.544)$ & 1,994 & $5.05(4.82-5.28)$ & 2,314 & $5.55(5.32-5.578)$ & 2,067 & 4.76(4.55-4.977) & 1,971 & $4.37(4.17-4.56)$ & 2,091 & 4.51(4.31-4.71) & 1,858 & 3.80 (3.63-3.98) & 1,705 & $3.38(3.22-3.55)$ \\
\hline $0-9$ years old & 1 & $0.00(0.00-0.03)$ & 1 & $0.00(0.00-0.03)$ & 0 & $0.00(0.000-0.00)$ & 1 & $0.00(0.00-0.04)$ & 0 & $0.00(0.00-0.00)$ & 0 & $0.00(0.00-0.00)$ & 0 & $0.00(0.00-0.00)$ & 0 & $0.00(0.00-0.00)$ & 0 & $0.00(0.00-0.00)$ & 1 & $0.00(0.00-0.04)$ & 0 & $0.00(0.000-0.00)$ & 1 & $0.02(0.00-0.06)$ \\
\hline 10-19 years old & 6 & $0.14(0.04-0.24)$ & 14 & $0.21(0.10-0.32)$ & 28 & $0.42(0.26-0.59)$ & 14 & $0.21(0.10-0.32)$ & 21 & $0.32(0.18-0.46)$ & 18 & $0.26(0.13-0.39)$ & 26 & $0.41(0.24-0.57)$ & 16 & $0.25(0.11-0.38)$ & 13 & $0.21(0.09-0.33)$ & 9 & $0.16(0.05-0.26)$ & 13 & $0.23(0.10-0.36)$ & 6 & (10 (0.01-0.20) \\
\hline 20-29 years old & 54 & $0.95(0.72-1.17)$ & 69 & $0.93(0.71-1.15)$ & 64 & $0.87(0.65-1.08)$ & 56 & $0.77(0.57-0.98)$ & 58 & $0.82(0.60-1.04)$ & 55 & $0.81(0.59-1.02)$ & 66 & 0.98 (0.74-1.22) & 57 & $0.84(0.61-1.06)$ & 32 & $0.46(0.30-0.63)$ & 29 & $0.42(0.26-0.57)$ & 38 & $0.54(0.36-0.72)$ & 34 & $0.48(0.31-0.64)$ \\
\hline 30-39 years old & 159 & $1.35(1.10-1.59)$ & 153 & (1. $1.47-2.03)$ & 125 & $\hat{\beta}(1.20-1.71)$ & 123 & $1.46(1.20-1.71)$ & 124 & $1.47(1.21-1.73)$ & 109 & $1.31(1.06-1.55)$ & 137 & $1.66(1.38-1.94)$ & 116 & $1.43(1.17-1.69)$ & 90 & $1.13(0.90-1.37)$ & 103 & $1.31(1.05-1.56)$ & 88 & $1.13(0.89-1.37)$ & 74 & $0.97(0.74-1.19)$ \\
\hline 40-49 years old & 488 & $3.90(3.47-4.32)$ & 304 & $3.64(3.23-4.05)$ & 289 & $3.40(3.01-3.79)$ & 261 & $3.04(2.67-3.41)$ & 277 & $3.23(2.84-3.61)$ & 247 & $2.86(2.50-3.22)$ & 291 & $3.35(2.97-3.74)$ & 210 & $2.39(2.06-2.71)$ & 227 & $2.56(2.23-2.90)$ & 206 & $2.35(2.03-2.67)$ & 205 & $2.34(2.02-2.66)$ & 188 & $2.16(1.85-2.48)$ \\
\hline $50-59$ years old & 816 & $6.79(6.09-7.48)$ & 393 & $6.90(6.22-7.58)$ & 414 & $6.90(6.233-7.57)$ & 415 & $6.51(5.89-7.14)$ & 408 & $5.99(5.41-6.57)$ & 389 & $5.34(4.81-5.87)$ & 453 & $5.98(5.42-6.53)$ & 428 & $5.46(4.94-5.98)$ & 424 & $5.28(4.77-5.78)$ & 415 & $5.09(4.60-5.58)$ & 381 & $4.60(4.14-5.07)$ & 330 & $3.95(3.53-4.38)$ \\
\hline 60-69 years & 714 & $12.9(11.7-14.1)$ & 484 & $13.2(12.0-14.4)$ & 527 & $13.9(12.7-15.1)$ & 517 & $13.3(12.11-14.4)$ & 449 & $11.2(10.2-12.3)$ & 421 & $10.4(9.47-11.4)$ & 471 & $11.3(10.3-12.3)$ & 440 & $10.2(9.27-11.11)$ & 417 & $9.18(8.30-10.0)$ & 449 & $9.18(8.33-10.0)$ & 383 & 7.38 (6.64-8.12) & 381 & $6.95(6.25-7.65)$ \\
\hline 70-79 years old & 628 & $23.0(20.8-25.2)$ & 444 & $22.5(20.4-24.6)$ & 551 & 26.3 (24.1-28.5) & 513 & $22.7(20.7-24.7)$ & 491 & $20.6(18.8-22.5)$ & 515 & $20.3(18.6-22.1)$ & 585 & $21.4(19.6-23.1)$ & 541 & $19.0(17.4-20.6)$ & 500 & $17.1(15.6-18.6)$ & 551 & $18.8(17.2-20.3)$ & 475 & $15.8(14.4-17.2)$ & 409 & $13.0(11.7-14.2)$ \\
\hline 80 years or & 285 & (216- & 200 & 3 & 226 & (28.1- & 251 & $28.9-3$ & 202 & $(21.3-$ & 240 & 5 (2240. & 289 & $126.6-$ & 259 & $25.3(22.2 \mathrm{r}$ & 268 & 23.9 (21.0-26. & 328 & 26.9 (24. $\mathrm{s}$ (2) & 27. & $20.7(18.4 \mathrm{r}$ & 282 & 19.7 (17.3-22.0) \\
\hline Females & 457 & $2.98(2.69-3.28)$ & 523 & $3.26(2.96-3.56)$ & 652 & $3.91(3.59-4.23)$ & 688 & $4.02(3.70-4.34)$ & 648 & $3.45(3.18-3.73)$ & 663 & $3.46(3.19-3.74)$ & 875 & $4.32(4.03-4.62)$ & 764 & 3.67 (3.40-3.93) & 732 & $3.34(3.09-3.59)$ & 889 & $3.99(3.72-4.26)$ & 776 & $3.32(3.08-3.56)$ & 681 & $2.81(2.59-3.02)$ \\
\hline & 0 & (0.00-0 & 0 & $(0.00-0$ & 0 & $(0.00-0.00)$ & & $(0.00-0.08)$ & 0 & $(0.00-0.00)$ & 0 & $0(0.00-0.00)$ & & (0.00-0.00) & 0 & $0.00(0.00-$ & & ${ }^{0}(0.00-0.00$ & 0 & 000.00 & & $10(0.00-0.6 \mathrm{C}$ & & $-0.00)$ \\
\hline 10-19 years old & 3 & $0.07(0.00-0.18)$ & 9 & $0.26(0.06-0.45)$ & 9 & $0.26(0.06-0.45)$ & 2 & $0.03(0.00-0.12)$ & 7 & $0.22(0.05-0.39)$ & 7 & $0.22(0.05-0.39)$ & 12 & $0.37(0.14-0.60)$ & 10 & $0.33(0.11-0.55)$ & 6 & $0.18(0.01-0.36)$ & 6 & $0.22(0.04-0.40)$ & 6 & $0.22(0.04-0.40)$ & 2 & $0.07(0.00-0.18)$ \\
\hline 20-29 years & 17 & $(0.24-0.68)$ & 18 & $0.26-2$ & 16 & $(0.20-0$ & 19 & $0.27-$ & 21 & $\mid 0.35-0.90$ & 18 & $2(0.27-0.78)$ & 29 & 0.89 (0.56-1.22) & 22 & $0.69(0.40-0.98$ & 13 & $0.39(0.17-0.61)$ & 13 & $0.39(0.17-0.67$ & 8 & $0.23(0.05-0.40)$ & 13 & $0.39(0.17-0.61)$ \\
\hline 30-39 years old & 25 & $0.58(0.35-0.81)$ & 29 & $0.66(0.41-0.91)$ & 36 & $0.85(0.57-1.14)$ & 33 & $0.80(0.52-1.07)$ & 38 & $0.91(0.61-1.21)$ & 32 & $0.77(0.49-1.05)$ & 51 & $1.27(0.92-1.62)$ & 38 & $0.94(0.63-1.24)$ & 31 & $0.80(0.51-1.08)$ & 38 & $0.99(0.67-1.31)$ & 45 & $1.19(0.83-1.54)$ & 23 & $0.60(0.35-0.86)$ \\
\hline 40-49 years ol & 67 & (1.24-2.04) & 72 & 1. & 81 & 3(1.50-2.235) & 71 & 1.6 & 88 & $2.10(1.66-2.54)$ & 71 & $1.67(1.27-2.06)$ & 121 & $2.86(2.35-3.3 .37)$ & 69 & $1.59(1.21-1.97)$ & 65 & $1.50(1.13-1.87)$ & 81 & 1.88(1.47-2.29) & 67 & $1.55(1.17-1.92)$ & 72 & $1.69(1.30-2.08)$ \\
\hline 50-59 years old & 89 & $3.28(2.59-3.96)$ & 109 & $3.83(3.11-4.55)$ & 120 & $4.00(3.28-4.72)$ & 125 & $3.90(3.21-4.59)$ & 139 & $4.08(3.40-4.76)$ & 118 & $3.23(2.64-3.81)$ & 160 & $4.23(3.57-4.89)$ & 146 & $3.73(3.12-4.34)$ & 156 & $3.88(3.27-4.49)$ & 170 & $4.18(3.55-4.81)$ & 147 & $3.58(3.00-4.16)$ & 130 & $3.10(2.56-3.64)$ \\
\hline 60-69 years old & 96 & $(4.13-6.20)$ & 99 & (4.11-6.14) & 152 & 7.67 (6.45-8.890) & 156 & 7.71(6.50-8.93) & 110 & $5.33(4.33-6.32)$ & 137 & $6.56(5.46-7.67)$ & 160 & 7.48(6.32-8.64) & 158 & $7.12(6.000-8.23)$ & 156 & $6.68(5.63-7.73)$ & 173 & 6.88(5.85-7.91) & 163 & $6.08(5.14-7.02)$ & 147 & $5.21(4.36-6.06)$ \\
\hline 70-79 years old & 112 & $10.1(8.25-12.0)$ & 127 & $10.8(8.97-12.7)$ & 157 & $12.7(10.7-74.7)$ & 175 & $13.2(11.2-15.1)$ & 169 & $12.2(10.4-14.1)$ & 185 & $12.7(10.8-14.5)$ & 208 & $13.3(1.15-15.1)$ & 194 & $11.9(10.2-13.6)$ & 190 & $11.4(9.84-13.1)$ & 235 & $14.2(12.4-16.0)$ & 186 & $11.0(9.49-12.6)$ & 154 & $8.83(7.44-10.2)$ \\
\hline 80 years & 48 & $11.4(8.20-14.7)$ & 60 & $(29.90-16.6)$ & 81 & $16.6(13.0-20.3)$ & 106 & 20.0 (16.2-23.8) & 76 & 13.3(10.3-16.3) & 95 & 15.5 (12.4-188.6) & 134 & $20.3(16.8-23.7)$ & 127 & $17.9(14.7-21.0)$ & 115 & $14.9(12.2-17.6)$ & 173 & $20.8(17.7-23.9)$ & 154 & $17.2(14.5-19.9)$ & 140 & 14.5 (12.1-1-16.9) \\
\hline Males & 1,468 & $9.21(8.71-9.71)$ & 1,539 & $9.24(8.75-9.72)$ & 1,572 & $9.09(8.62-9.56)$ & 1,463 & $7.98(7.55-8.40)$ & 1,382 & $7.11(6.72-7.50)$ & 1,331 & $6.60(6.23-6.97)$ & 1,439 & $6.73(6.38-7.09)$ & 1,303 & $5.81(5.49-6.13)$ & 1,239 & $5.32(5.02-5.62)$ & 1,202 & $4.97(4.69-5.26)$ & 1,082 & $4.24(3.988-4.49)$ & 1,024 & $3.89(3.65-4.13)$ \\
\hline $0-9$ years old & 1 & $0.00(0.00-0.07)$ & 1 & $0.00(0.00-0.07)$ & 0 & $0.00(0.000-0.00)$ & 0 & $0.00(0.00-0.00)$ & 0 & $0.00(0.00-0.00)$ & 0 & $0.00(0.00-0.00)$ & 0 & $0.00(0.00-0.00)$ & 0 & $0.00(0.00-0.00)$ & 0 & $0.00(0.00-0.00)$ & 1 & $0.00(0.00-0.08)$ & & 0 & 1 & $0.04(0.00-0.13)$ \\
\hline 10-19 years old & 7 & $(0.05-0.35)$ & 5 & $(0.01-0.26)$ & 19 & . $29-0.79)$ & 12 & $0.14-0.54)$ & 14 & $6-0.59)$ & 11 & $(0.11-0.50)$ & 14 & $(0.18-0.63)$ & 6 & $.01-0.32)$ & 7 & $0(0.03-0.037)$ & 3 & 0 & 7 & $4(0.05-0.42)$ & 4 & $13(0.00-0.28)$ \\
\hline 20-29 years old & 55 & $1.41(1.04-1.79)$ & 51 & $1.32(0.95-1.69)$ & 48 & $1.26(0.90-1.62)$ & 37 & $1.00(0.67-1.32)$ & 37 & $1.00(0.67-1.33)$ & 37 & $1.03(0.69-1.36)$ & 37 & $1.03(0.69-1.37)$ & 35 & 0.97(0.64-1.30) & 19 & $0.53(0.29-0.77)$ & 16 & 0.44 (0.22-0.66) & 30 & $0.82(0.52-1.12)$ & 21 & $0.56(0.31-0.80)$ \\
\hline ars old & 94 & & 124 & & 89 & & 90 & & 86 & & 7 & & 86 & & 78 & & & & 65 & & & & 51 & \\
\hline 40-49 years old & 255 & $6.03(5.28-6.77)$ & 232 & $5(4.74-6.15)$ & 208 & 4.79(4.14-5.55) & 190 & $4.33(3.71-4.95)$ & 189 & $4.30(3.69-4.92)$ & 176 & $3.98(3.39-4.57)$ & 170 & 3.84(3.26-4.42) & 141 & 3.14 (2.62-3.66) & 162 & $3.61(3.05-4.16)$ & 125 & 2.79 (2.30-3.28) & 138 & 3.09 (2.57-3.61) & 116 & $2.63(2.15-3.11)$ \\
\hline & 277 & & 284 & & 29. & & 290 & & 26 & & 271 & & 29 & & 282 & & 26 & & & & & & 200 & \\
\hline & 361 & $21.6(19.4-4$ & 385 & 22.1 (19.9-2-24.3) & 375 & $(18.6-22.8)$ & 361 & $(17.3-21.3)$ & 339 & $.6(15.7-19.5)$ & 284 & 2.9-16.3) & 311 & 15.4(13.7-17.2) & 282 & 15.0) & 261 & 0.3-13.2) & 276 & -12.9) & 220 & -9.8.86) & 234 & $75(7.63-9.88)$ \\
\hline & 311 & & 317 & & 39. & & 338 & & 32 & & 33 & & & & 347 & & 31 & & 316 & & & & 255 & \\
\hline ss or older & 107 & $(46.8-68.7)$ & 140 & (58.8-82.2) & 145 & (57.0-79.2) & 145 & 62.6 (52.3-72.8) & 126 & $(42.3-60.2)$ & 145 & $55.0(46.0-63.9)$ & 151 & 52.4(444.0-60.8) & 132 & $41.8(34.7-49.0)$ & 153 & $43.5(36.6-50.4)$ & 155 & 39.8 (33.5-46.1) & 121 & $28.1(23.1-33.1)$ & 142 & 30.0 (25.0-34.9) \\
\hline
\end{tabular}

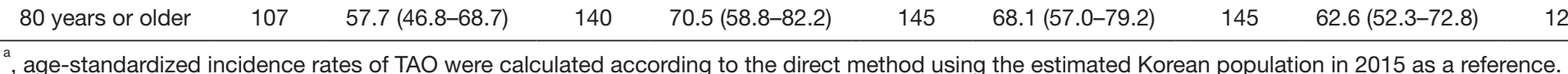

